\title{
Fate of pancreatic nodules induced by raw soya flour in rats
}

\author{
E E MCGUINNESS, R G H MORGAN, AND K G WORMSLEY \\ From the Dept of Therapeutics, Ninewells Hospital, University of Dundee, Dundee, Scotland
}

SUMMARY We have previously shown that rats fed raw soya flour (RSF) for more than four months develop hyperplastic foci of pancreatic acinar cells, which undergo malignant change if feeding RSF is continued throughout the life of the animals. The tendency to undergo malignant change is augmented by the additional use of a genotoxic carcinogen such as azaserine. The present study has sought to examine the reversibility of the focal neoplastic change in the pancreas. Rats fed RSF for 24 weeks and then given a diet not containing soya flour (NSC) had a normal pancreas when killed after 60 weeks of study. When RSF was fed for only 36 weeks, however, some of the rats developed pancreatic cancer even though the diet had been switched to NSC. Similarly, while azaserine in the dose used in the present study does not produce pancreatic cancer in our strain of Wistar rats, coincident administration of RSF for 12 weeks (but not for six weeks) resulted in progression to pancreatic adenoma. Although change from RSF to NSC after 30 weeks resulted in rapid reduction in pancreatic weight and content of RNA, neoplastic foci persisted and became frankly malignant. We conclude that phenotypic reversion to normal of the RSF diet- and azaserine-treated rat pancreas is only possible if RSF alone is fed continuously for not more than about 24 weeks or six weeks if the rats have been exposed to a pancreatic initiating carcinogen.

In our previous studies, we have shown that continuous administration of a diet of raw soya flour (RSF) for up to two years stimulates abnormal growth of the rat pancreas with eventual neoplastic change. ${ }^{12}$ We have also shown that a diet containing RSF potentiates the effect of pancreatic carcinogens such as azaserine. ${ }^{34}$

The present study was undertaken to monitor aspects of the reversibility of the morphological changes produced in the pancreas by raw soya flour and azaserine.

\section{Methods}

\section{ANIMALS}

A total of 103 male Wistar rats (three months old and with average body weight of $400 \mathrm{~g}$ ) was used in the study. Three different experimental protocols were used:

GROUP 1: REVERSIBILITY OF THE PANCREATIC EFFECTS OF RAW SOYA FLOUR (Table 1)

Our earlier studies had shown that RSF, fed either continuously or intermittently for two years, proAddress for correspondence: Dr K G Wormsley, Ninewells Hospital, Dundee DD1 9SY, Scotland duced pancreatic cancer in a proportion of rats. ${ }^{125}$ The present protocol was designed to assess the effects of shorter periods of exposure to the RSF diet.

Twenty-seven rats were fed a diet composed of RSF for 24,36 , or 52 weeks after which they received a diet of non-soya-containing chow (NSC). A control group of 27 rats received a NSC diet throughout the study. These animals did not receive azaserine.

The rats were killed after more than 60 weeks of study.

GROUP 2: EFFECT OF SHORT TERM TREATMENT WITH RSF ON AZASERINE-INDUCED PANCREATIC CARCINOGENESIS (Table 2)

Twelve rats were fed a diet of RSF for three, six or 12 weeks, after which they were given a NSC diet. During the first 24 weeks of the study, each rat received an intraperitoneal injection of $5 \mathrm{mg} / \mathrm{kg}$ azaserine (Calbiochem, Behring Corp, Bishops Stortford, England), once each week in $0.2 \mathrm{ml}$ saline.

A control group of three rats also received the 24 azaserine injections but these rats were fed a diet of NSC from the beginning of the study.

The rats were killed after more than 60 weeks of study. 
Table 1 Reversibility of pancreatic effects of raw soya flour (RSF)

\begin{tabular}{|c|c|c|c|c|c|c|c|c|}
\hline \multirow[t]{2}{*}{ Diet } & \multirow{2}{*}{$\begin{array}{l}\text { Duration of } \\
\text { Study } \\
\text { (weeks) }\end{array}$} & \multirow[t]{2}{*}{$\begin{array}{l}\text { Rats } \\
(n)\end{array}$} & \multicolumn{3}{|c|}{ Pancreases with Nodules \% } & \multicolumn{2}{|c|}{$\begin{array}{l}\text { Volume Density of } \\
\text { microscopic nodules }\end{array}$} & \multirow{2}{*}{$\begin{array}{l}\text { Pancreases } \\
\text { with Carcinomas } \\
\text { (n) }\end{array}$} \\
\hline & & & $\begin{array}{l}\text { Micro- } \\
\text { scopic }\end{array}$ & $\begin{array}{l}\text { Macro- } \\
\text { scopic }\end{array}$ & $\begin{array}{l}\text { Adeno- } \\
\text { matous }\end{array}$ & Median & Range & \\
\hline \multirow[t]{2}{*}{ NSC } & $61-90$ & 22 & 9 & 0 & 0 & - & - & 0 \\
\hline & $>90$ & 5 & 0 & 0 & 0 & - & - & 0 \\
\hline $\begin{array}{l}\text { RSF } 24 \text { weeks, } \\
\text { then NSC }\end{array}$ & $61-90$ & 3 & 0 & 0 & 0 & - & - & 0 \\
\hline \multirow{2}{*}{$\begin{array}{l}\text { RSF } 36 \text { weeks, } \\
\text { then NSC }\end{array}$} & $61-90$ & 2 & 100 & 50 & 50 & $2 \cdot 1$ & $0-4 \cdot 3$ & 0 \\
\hline & $>90$ & 6 & 100 & 100 & 83 & $29 \cdot 2$ & $4.9-63.4$ & 2 \\
\hline \multirow{2}{*}{$\begin{array}{l}\text { RSF } 52 \text { weeks, } \\
\text { then NSC }\end{array}$} & $61-90$ & 6 & 83 & 50 & 33 & $11 \cdot 5$ & $0-100$ & 2 \\
\hline & $>90$ & 9 & 89 & 89 & 78 & $29 \cdot 0$ & $0-100$ & 1 \\
\hline
\end{tabular}

RSF = Raw soya flour diet $;$ NSC $=$ Non-soya-containing diet.

Table 2 Short term treatment with raw soya flour during azaserine-induced carcinogenesis

\begin{tabular}{|c|c|c|c|c|c|c|c|}
\hline \multirow[t]{2}{*}{ Diet } & \multirow{2}{*}{$\begin{array}{l}\text { Rats } \\
(n)\end{array}$} & \multicolumn{3}{|c|}{ Pancreases with Nodules \% } & \multicolumn{2}{|c|}{$\begin{array}{l}\text { Volume density of } \\
\text { Microscopic Nodules }\end{array}$} & \multirow{2}{*}{$\begin{array}{l}\text { Pancreas } \\
\text { with carcinoma } \\
\text { (n) }\end{array}$} \\
\hline & & $\overline{\text { Microscopic }}$ & Macroscopic & Adenomatous & Median & Range & \\
\hline $\begin{array}{l}\text { RSF } 3 \text { weeks; } \\
\text { then NSC }\end{array}$ & 5 & 40 & 0 & 0 & $3 \cdot 0$ & $0-10.8$ & 0 \\
\hline $\begin{array}{l}\text { RSF } 6 \text { weeks; } \\
\text { then NSC }\end{array}$ & 2 & 0 & 0 & 0 & 0 & - & 0 \\
\hline $\begin{array}{l}\text { RSF } 12 \text { weeks; } \\
\text { then NSC }\end{array}$ & 5 & 80 & 40 & 40 & $18 \cdot 1$ & $0-68.4$ & 0 \\
\hline
\end{tabular}

All rats received azaserine for 24 weeks. All studies lasted longer than 60 weeks. RSF = Raw soya flour diet; NSC $=$ Non-soyacontaining diet.

Table 3 Variable duration raw soya flour diets

\begin{tabular}{|c|c|c|c|c|c|c|c|c|}
\hline \multirow{2}{*}{$\begin{array}{l}\text { Diet } \\
\text { RSF }\end{array}$} & \multirow{2}{*}{$\begin{array}{l}\text { (Weeks) } \\
\text { NSC }\end{array}$} & \multirow{2}{*}{$\begin{array}{l}\text { Rats } \\
(n)\end{array}$} & \multicolumn{3}{|c|}{ Pancreases with nodules $\%$} & \multicolumn{2}{|c|}{$\begin{array}{l}\text { Volume density of } \\
\text { microscopic nodules }\end{array}$} & \multirow{2}{*}{$\begin{array}{l}\text { Pancreases } \\
\text { with carcinoma } \\
\text { (n) }\end{array}$} \\
\hline & & & Microscopic & Macroscopic & Adenomatous & Median & Range & \\
\hline 30 & $\mathbf{0}$ & 4 & 100 & 100 & 100 & $75 \cdot 9$ & $70 \cdot 8-80 \cdot 3$ & 0 \\
\hline 32 & 0 & 4 & 100 & 100 & 50 & 83.9 & $72.5-91.9$ & 0 \\
\hline 40 & $\mathbf{0}$ & 4 & 100 & 100 & 100 & 90.0 & $76 \cdot 8-96 \cdot 7$ & 0 \\
\hline 60 & 0 & 4 & 100 & 100 & 100 & $88 \cdot 4$ & $86 \cdot 6-93 \cdot 0$ & 0 \\
\hline 70 & 0 & 3 & 100 & 100 & 100 & $91 \cdot 1$ & $83 \cdot 8-100$ & 1 \\
\hline 30 & 2 & 4 & 100 & 100 & 50 & $83 \cdot 2$ & $42 \cdot 0-94 \cdot 1$ & 0 \\
\hline 30 & 10 & 4 & 100 & 100 & 25 & $36 \cdot 4$ & $30.9-87 \cdot 7$ & 0 \\
\hline 30 & 20 & 1 & 100 & 100 & 100 & $66 \cdot 8$ & - & 0 \\
\hline 30 & 30 & 4 & 100 & 100 & 100 & 60.9 & $51 \cdot 5-66 \cdot 9$ & 1 \\
\hline 40 & 30 & 2 & 100 & 100 & 50 & $51 \cdot 7$ & $3 \cdot 3-100$ & 1 \\
\hline
\end{tabular}

All rats received five injections of $30 \mathrm{mg} / \mathrm{kg}$ azaserine once each week. RSF = Raw soya flour diet; NSC = Non-soya-containing diet

GROUP 3: EFFECTS OF MEDIUM- AND LONGTERM RSF DIETS ON RATS GIVEN HIGH DOSES OF AZASERINE (Table 3)

The present experimental schedule was designed to assess the degree of reversibility or progression of severe pancreatic damage of limited duration caused by a very high dose of azaserine together with a RSF diet.

Thirty-four rats were fed a diet of RSF for 30 weeks and in addition received intraperitoneal injections of $30 \mathrm{mg} / \mathrm{kg}$ azaserine in $0.2 \mathrm{ml}$ saline once each week during the first five weeks of study. After the initial period of 30 weeks, the rats were separated into two groups and received either a NSC diet or continued with the RSF diet for the remainder of the study.

The rats were killed 30 weeks after the onset of the study (that is, at the time the rats were separated into the two experimental subgroups), or after a further 
two, 10,30 or 40 weeks (that is, after a total study period of 32, 40, 60 and 70 weeks) (Table 3).

Dietary composition with added vitamin and mineral supplements has been described previously. ${ }^{6}$ All rats were killed after anaesthesia with ether. The pancreas and other organs were removed, examined macroscopically and fixed in buffered formalin in preparation for histological study. Six representative blocks were taken from each pancreas. All sections were stained with haematoxylin and eosin for microscopic study. Volume densities of the pancreatic nodules were assessed according to the method of Weibel ${ }^{7}$ as described previously. ${ }^{4}$

In addition to histological studies, pancreatic tissue from rats in group 3 was analysed for content of DNA and RNA by the method of Munro and Fleck. ${ }^{8}$ Total content of protein was measured by the method of Papadopoulos et al. ${ }^{9}$

\section{Results}

GROUP 1 (REVERSIBILITY OF RSF EFFECTS)

Pancreatic weights (Fig. 1)

Irrespective of the duration of the study, all rats fed RSF for 24 weeks, followed by NSC, had pancreatic weights which were not significantly different from rats fed NSC throughout the study. Similarly, rats fed RSF for 36 weeks only, followed by NSC, had pancreatic weights not significantly different from control NSC-fed rats in studies lasting longer than $\mathbf{9 0}$ weeks.

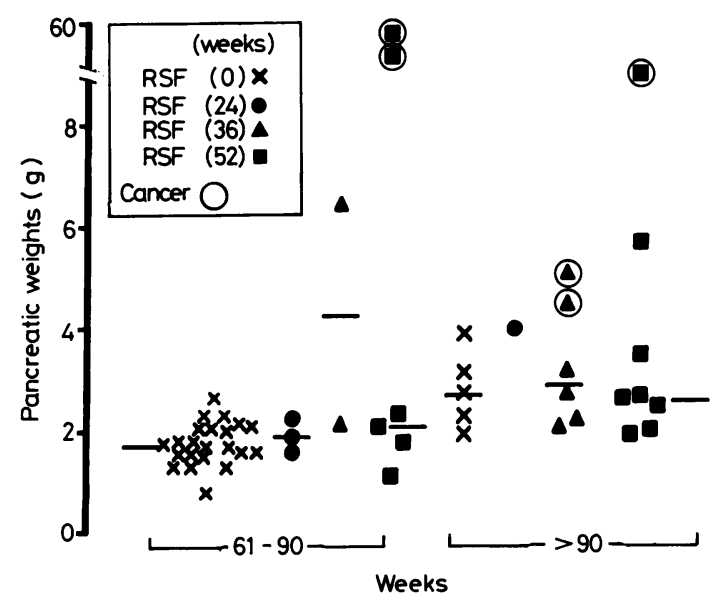

Fig. 1 Pancreatic weight of rats fed raw soya flour for 2452 weeks and non-soya-containing diet thereafter for the remainder of the study. Each point represents the result from one animal in the four dietary groups. The symbols enclosed by a circle indicate rats which developed pancreatic cancer. Horizontal bars represent median values. The total duration of the study is depicted on the abscissa. $R S F=$ Raw soya flour.
Eleven of the rats fed RSF for 52 weeks, followed by NSC, had pancreatic weights not different from control while four animals had significantly heavier pancreases.

\section{Macroscopic and microscopic appearances of the pancreas (Table 1)}

(i) $R S F$ for 24 weeks; then NSC

After 60 weeks of study, none of the pancreases contained microscopic or macroscopic nodules. Macroscopic pancreatic nodules, however, were visible in the single rat studied for more than 90 weeks, some of which were adenomatous.

\section{(ii) RSF for 36 weeks; then NSC}

After 60 weeks of study, one or two rats had macroscopic pancreatic nodules, while both rats had microscopic nodules. In rats studied for longer than 90 weeks, all pancreases contained microscopic and macroscopic nodules. Five of the six pancreases showed adenomatous nodules and two of the pancreases contained carcinomata, one of which was undifferentiated while the other was an acinar cell carcinoma.

(iii) RSF for 52 weeks; then NSC

After 60 weeks of study, half of the animals had macroscopic pancreatic nodules and two of the rats had pancreatic carcinomas, with hepatic metastases, one being a papillary carcinoma and the other an acinar cell neoplasm.

\section{(iv) Continuous NSC (control)}

None of the pancreases from these control animals contained microscopic or macroscopic nodules.

\section{GROUP 2 (SHORT TERM RSF DIETS)}

Pancreatic Weights

All rats had pancreases of a similar weight, irrespective of dietary regimen.

\section{Incidence of pancreatic nodules (Table 2)}

(i) $R S F$ for 3 weeks

None of these rats had macroscopic pancreatic nodules. After 60 weeks or more of study, two of the five pancreases contained a few microscopic nodules.

(ii) RSF for six weeks

None of the pancreases from rats in this group had either macroscopic or microscopic nodules in the pancreas.

\section{(iii) $R S F$ for 12 weeks}

Two of the five rats had developed macroscopic nodules in the pancreas, while four of the five rats had 


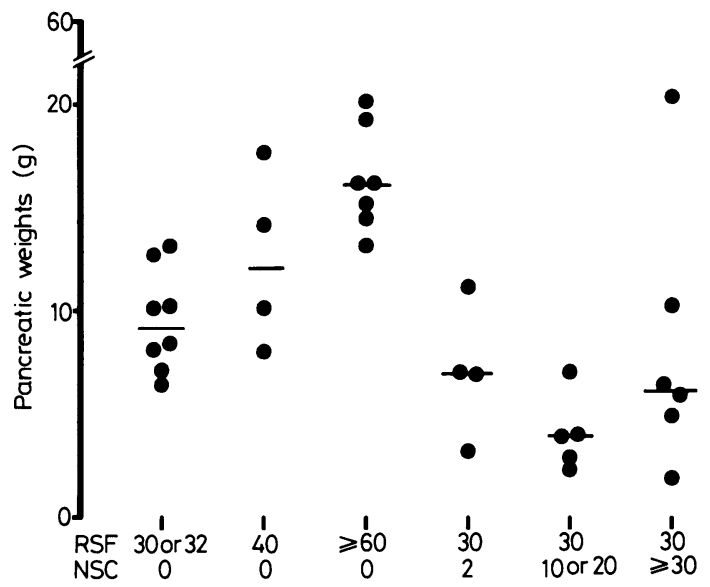

Fig. 2 Pancreatic weight of rats fed raw soya flour (RSF) for 30 weeks and then either kept on RSF or switched to non-soya-containing diet (NSC). The duration of treatment is shown at the base of each vertical column. Each animal also received azaserine for 5 weeks at the beginning of the study. Symbols as in Fig. 1

microscopic pancreatic nodules. The nodules were adenomatous in two of the rats.

\section{GROUP 3 (REVERSIBILITY OF HIGH DOSE}

AZASER INE)

Pancreatic weights (Fig 2)

(i) Azaserine; RSF 30 weeks, then NSC

Apart from the one rat which developed a large pancreatic tumour, the pancreases of rats which had undergone a dietary switch to NSC tended to decrease in size compared with the pancreatic weight of rats killed after the first 30 weeks of study during which RSF was fed.

(ii) Azaserine; RSF continuously

Compared with the pancreatic weight of the rats fed RSF for only 30 weeks, rats fed RSF continuously for 60 or 70 weeks had significantly heavier pancreas $(\mathrm{p}<0.05)$.

\section{Microscopic and macroscopic appearances of the} pancreas (Table 3)

(i) Azaserine; RSF 30 weeks, then NSC

Microscopically, pancreatic nodules were present in all the rats. Adenomatous nodules were present in 11 of the 15 animals. Two rats developed pancreatic carcinomas, one of which was an in situ acinar cell carcinoma while the other was an acinar carcinoma with mesenteric metastases.

(ii) Azaserine; RSF continuously

Microscopic and macroscopic nodules were present in all pancreases. All except two of the pancreases

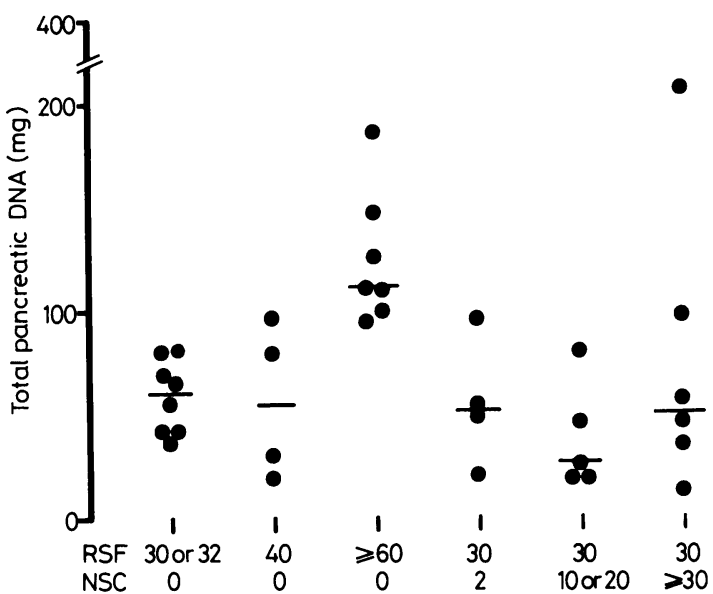

Fig. 3 Total DNA content of the pancreas of rats, the pancreatic weights of which is shown in Fig. 2.

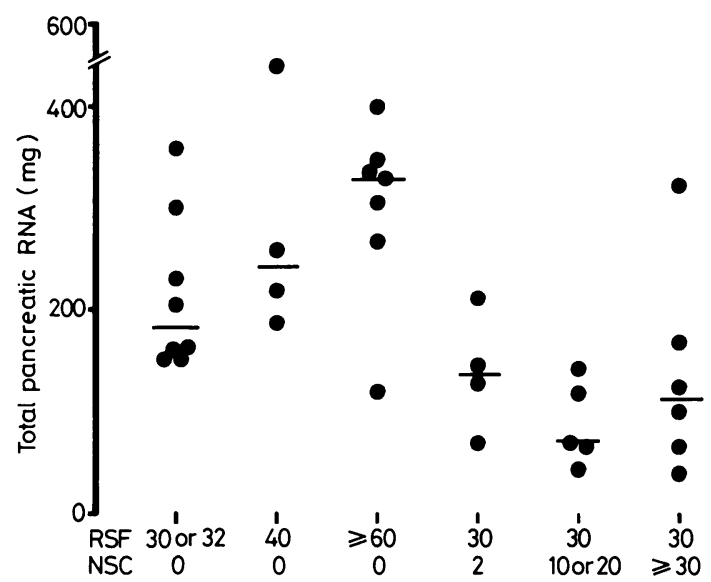

Fig. 4 Total RNA content of pancreas of rats shown in Fig. 2

contained adenomatous nodules. One rat, treated for more than 70 weeks, developed an acinar cell carcinoma which was not visible macroscopically.

PANCREATIC DNA, RNA AND TOTAL PROTEIN CONTENT (Figs 3, 4 \& 5)

The RNA content of the rats fed RSF for $\mathbf{4 0}$ weeks was greater than the content after 30 weeks, although the difference was not significant. Rats fed RSF for 60 and 70 weeks had significantly greater amounts of DNA in their pancreas than rats fed RSF for 30 weeks $(p<0.01)$. Similarly, the RNA and total protein content of rats fed RSF for 60 weeks was significantly greater $(p<0.02)$ than rats fed RSF for 30 weeks. 


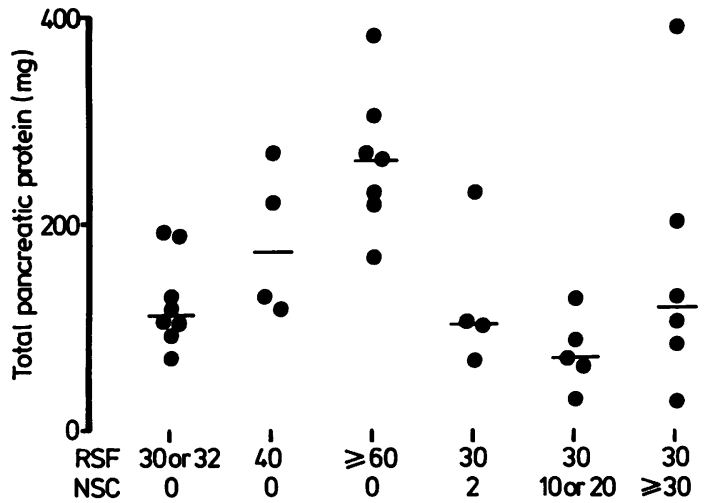

Fig. 5 Total protein content of pancreas of rats shown in Fig. 2

The pancreatic DNA content of rats switched to a non-soya-containing diet after 30 weeks of RSF did not differ significantly from the DNA content of rats killed after feeding RSF for 30 weeks. The RNA content of the dietarily switched rats was, however, significantly less $(p<0.02)$ than rats fed RSF for 30 weeks (Fig. 4). The total protein content of the different groups of rats did not differ significantly from those killed after feeding RSF for 30 weeks.

\section{Discussion}

The present study has shown that, in the rat, exposure to raw soya flour for as little as 36 weeks results in irreversible changes in the pancreas, which progress to carcinoma even when the RSF diet is switched to NSC for the remaining year or so of the animals' lives. The mechanism of the neoplastic change is not known. No information is available whether the components of RSF are acting as a complete carcinogen or are promoting foci of cells initiated by environmental chemical or infectious carcinogens, or which have undergone 'spontaneous' mutational change analogous to initiation. Alternatively, it may be that the excessive and prolonged functional and proliferative stimulus provided by the RSF by itself ultimately destroys the controls on the normal growth of the pancreas or activates autocrine mechanisms which result first in benign and then malignant neoplastic growth.

On the other hand, although we have previously reported the development of abnormal foci of cells treated with RSF for 24 weeks, ${ }^{10}$ these foci seem to disappear when the feeding of RSF is stopped at this time. The disappearance of the abnormal foci of acinar cells appears to be more than mere phenotypic reversion to normal acinar patterns because a marked involution of the gland occurs rapidly when feeding with RSF ceases. As we have shown in the studies of group 3, significant decrease in the weight of the glands and in the RNA content occurs within a few weeks of switching to NSC after feeding RSF for 30 weeks. Similar involution has been reported previously ${ }^{11}$ and attributed to apoptosis in the affected pancreases. ${ }^{12}$ These findings imply that a stimulus to growth and neoplastic change persists throughout the period of feeding of RSF but ceases when the dietary RSF is removed. Changes are then reversible unless the abnormal pancreatic foci have already become 'autonomous'.

From the data of the present study, it appears that addition of azaserine significantly accelerates the pancreatic carcinogenic effect of RSF. We have previously shown that coincident administration of azaserine with RSF augments the development of abnormal pancreatic foci ${ }^{10}$ and pancreatic cancer. ${ }^{34}$ Comparison of the results of our current groups 1 and 2 shows that azaserine produces irreversible pancreatic foci in rats fed RSF for only 12 weeks, while without azaserine RSF had to be fed for three times as long to achieve the same effect. It seems possible, also, that the pancreatic carcinomas appeared earlier in the rats given both RSF (for 30 weeks) and azaserine than in rats given RSF alone for 36 weeks, although the difference in the time of onset of the cancers was obviated by feeding RSF for 52 weeks.

The results of the present study of the fate of pancreatic foci resemble those described previously in the liver after exposure to carcinogens. For example, after exposure of the liver to $\mathrm{N}$-2-fluorenylacetamide for a short period of time, foci of phenotypically altered cells are produced. After cessation of exposure to the carcinogen, some of the nodules persisted and demonstrated autonomous capacity for growth. ${ }^{13}$ On the other hand, regression of hepatic nodules has also been observed ${ }^{14}$ and attributed to redifferentiation of the affected cells of the foci to adult hepatic phenotype.

It is perhaps worth considering the potential survival value of nodule formation and regression during prolonged exposure to RSF. It has been proposed that the development of foci of biochemically-altered hepatic cells represents a physiological adaptation to excessive exposure to xenobiotics. Because the foci of altered hepatocytes are resistant to the cytotoxic effects of the xenobiotics, the survival of the animal is improved. ${ }^{15}$ We have previously suggested that the foci of altered pancreatic cells may differ from the remainder of the pancreatic acinar cells in retaining CCK receptors in the face of continued stimulation with CCK. ${ }^{16}$ It seems possible that the development of the initial hyperplastic foci is a normal pancreatic response to the feeding of trypsin inhibitor, which permits the animal to survive by 
continuing to secrete proteolytic enzymes sufficient to overcome the dietary inhibition under circumstances when otherwise the pancreatic secretion would have failed. In this connection, we have found that pancreatic secretion of proteolytic enzymes is linearly related to pancreatic weight (that is, acinar cell mass) irrespective of whether the pancreatic tissue is normal, consists of mainly hyperplastic foci, or is frankly neoplastic. We assume that regression to phenotypically normal pancreas after cessation of the RSF diet represents preprogrammed reversion to the pancreatic acinar status appropriate to the normal diet, while further change, from hyperplastic to benign and then malignant neoplastic pancreatic foci reflects the increased susceptibility of the mitotically active cells of the initial hyperplastic foci to carcinogens such as azaserine.

The implications of the findings of the present study to man depend to what extent the human pancreas reacts to RSF like the pancreas of the rat. The matter has been discussed previously. ${ }^{2}$ It does seem, however, that in the presence of an initiating carcinogen (such as azaserine in the present study) RSF does not have to be administered for long (12 weeks) for autonomously progressive foci of acinar cells to develop. As some human population groups are exposed to trypsin-inhibitor-containing diets for some time (groups such as infants fed soya milks and adults taking some weight-reducing diets) our findings may highlight a potential hazard for man.

KGW gratefully acknowledge the generous support of the Cancer Research Campaign. RGHM acknowledges the support of the National Health and Medical Research Council of Australia and the Cancer Council of Western Australia.

\section{References}

1 McGuinness EE, Morgan RGH, Levison DA, Frape DL, Hopwood D, Wormsley KG. The effects of longterm feeding of soya flour on the rat pancreas. Scand $J$ Gastroenterol 1980; 15: 497-502.
2 McGuinness EE, Morgan RGH, Wormsley KG. Effects of soybean flour on the pancreas of rats. Env Hlth Persp 1984; 56: 205-12.

3 McGuinness EE, Hopwood D, Wormsley KG. Further studies of the effects of raw soya flour on the rat pancreas. Scand J Gastroenterol 1982; 17: 273-7.

4 McGuinness EE, Morgan RGH, Levison DA, Hopwood $\mathrm{D}$, Wormsley $\mathrm{KG}$. Interaction of azaserine and raw soya flour on the rat pancreas. Scand J Gastroenterol 1981; 16: 49-56.

5 McGuinness EE, Wormsley KG. Effects of feeding partial and intermittent raw soya flour diets on the rat pancreas. Cancer Lett 1986; 32: 73-81.

6 Fölsch UR, Wormsley KG. The pancreatic secretion of enzymes in rats treated with soybean diet. Scand $J$ Gastroenterol 1974; 9: 679-83.

7 Weibel ER. Principles and methods for the morphometric study of the lung and other organs. Lab Invest 1963; 12: 131-55.

8 Munro HN, Fleck A. Recent developments in the measurement of nucleic acids in biological materials. Analyst 1966; 91: 78-88.

9 Papadopoulos NM, Hess WC, O'Doherty D, McLane JE. A procedure for the determination of cerebrospinal fluid total protein and gamma globulin in neurologic disorders. Clin Chem 1959; 5: 569-74.

10 Morgan RGH, Levison DA, Hopwood D, Saunders JHB, Wormsley KG. Potentiation of the action of azaserine on the rat pancreas by raw soya bean flour. Cancer Lett 1977; 3: 87-90.

11 Crass RA, Morgan RGH. Rapid changes in pancreatic DNA, RNA and protein during pancreatic enlargement and involution. Int $J$ Vit Nutr Res 1981; 51 : 85-91.

12 Oates PS, Morgan RGH, Light AM. Cell death (apoptosis) during pancreatic involution following raw soya flour feeding in the rat. Am J Physiol 1986; 250: G9-14.

13 Hirota N, Williams GM. Persistence and growth of rat liver neoplastic nodules following cessation of carcinogen exposure. J Natl Cancer Inst 1979; 63: 1257-65.

14 Tatematsu M, Nagamine Y, Farber E. Redifferentiation as a basis for remodelling of carcinogen-induced hepatocyte nodules to normal appearing liver. Cancer Res 1983; 43: 5049-58.

15 Farber E. The multistep nature of cancer development. Cancer Res 1984; 44: 4217-23.

16 McGuinness EE, Morgan RGH, Wormsley KG. Trophic effects on the pancreas of trypsin and bile salt deficiency in the small-intestinal lumen. Scand J Gastroenterol 1985; 20: suppl 112: 64-7. 